Article

\title{
Saccharomyces arboricola and Its Hybrids' Propensity for Sake Production: Interspecific Hybrids Reveal Increased Fermentation Abilities and a Mosaic Metabolic Profile
}

\author{
Matthew J. Winans ${ }^{1,2, * \mathbb{C} \text {, Yuki Yamamoto }}{ }^{1}$, Yuki Fujimaru ${ }^{1}$, Yuki Kusaba ${ }^{1}$, \\ Jennifer E. G. Gallagher ${ }^{2}$ and Hiroshi Kitagaki ${ }^{1}$ \\ 1 Graduate School of Advanced Health Sciences, Saga University, 1, Honjo, Saga city, Saga 840-8502, Japan; \\ 18555010@edu.cc.saga-u.ac.jp (Y.Y.); yukidenkan37@gmail.com (Y.F.); 19626004@edu.cc.saga-u.ac.jp (Y.K.); \\ ktgkhrs@cc.saga-u.ac.jp (H.K.) \\ 2 Biology Department, West Virginia University, 53 Campus Drive, Morgantown, WV 26506-6057, USA; \\ jegallagher@mix.wvu.edu \\ * Correspondence: mwinans@mix.wvu.edu; Tel.: +1-(304)-483-1786; Fax: +1-(304)-293-6363
}

Received: 4 December 2019; Accepted: 17 January 2020; Published: 20 January 2020

\begin{abstract}
The use of interspecific hybrids during the industrial fermentation process has been well established, positioning the frontier of advancement in brewing to capitalize on the potential of Saccharomyces hybridization. Interspecific yeast hybrids used in modern monoculture inoculations benefit from a wide range of volatile metabolites that broaden the organoleptic complexity. This is the first report of sake brewing by Saccharomyces arboricola and its hybrids. S. arboricola $\times$ S. cerevisiae direct-mating generated cryotolerant interspecific hybrids which increased yields of ethanol and ethyl hexanoate compared to parental strains, important flavor attributes of fine Japanese ginjo sake rice wine. Hierarchical clustering heatmapping with principal component analysis for metabolic profiling was used in finding low levels of endogenous amino/organic acids clustered S. arboricola apart from the S. cerevisiae industrial strains. In sake fermentations, hybrid strains showed a mosaic profile of parental strains, while metabolic analysis suggested S. arboricola had a lower amino acid net uptake than S. cerevisiae. Additionally, this research found an increase in ethanolic fermentation from pyruvate and increased sulfur metabolism. Together, these results suggest $S$. arboricola is poised for in-depth metabolomic exploration in sake fermentation.
\end{abstract}

Keywords: sake; fermentation; hybrid; ginjo; ethanol; ethyl hexanoate; isoamyl acetate; yeast; Saccharomyces; metabolism

\section{Introduction}

As currently defined, the budding yeast clade known as Saccharomyces has eight members: S. cerevisiae, S. paradoxus (syn. S. cerevisiae var. tetraspora, S. cerevisiae var. terrestris), S. uvarum (syn. S. bayanus var. uvarum), S. mikatae, S. kudriavzevii, S. arboricola (syn. S. arboricolus), S. eubayanus, and S. jurei [1-9]. Additionally, S. pastorianus (syn. S. carlsbergensis, S. monacensis) and S. bayanus are two natural hybrids found in this group [10-12]. S. arboricola was first isolated from the tree bark of the Fagaceea family in the west and southwest of China [2] in 2008 and later also isolated in western Taiwan [5] and northern New Zealand [13]. The New Zealand isolate was reported to be highly divergent from the Chinese isolates used in this study, supporting the far East Asian origin theory for Saccharomyces yeast. The Chinese $S$. arboricola has a high quality annotated genomic sequence that when compared to S. cerevisiae shows a reciprocal translocation on chromosome (chr.) IV and XIII, inversion 
on chr.VI, high presence of non-syntenic genes near telomeric regions, lack of introgression, and four novel genes [14]. Between S. cerevisiae and other Saccharomyces members there is a 15-30\% divergence, but the divergence between $S$. cerevisiae strains is $0.1-0.6 \%[15,16]$. Additionally, subpopulations of S. paradoxus show a $1.5-4.5 \%$ divergence, while the divergence between $S$. eubayanus and $S$. uvarum is $6 \%[7,17]$. The nucleotide divergence of yeast within Saccharomyces is near the man to bird comparison, but with the advantage of a physiological and structural similarity of man to chimp [18]. Favorable properties of different Saccharomyces yeast can be brought together by hybridization that often results in transgressive phenotypes. Typical environmentally isolated Saccharomyces strains are diploid while laboratory strains are often used in the haploid form to reduce variability and industrial yeast are frequently found to be polyploidy, potentially a result of favored fermentation environment. Although interspecies hybrids of the Saccharomyces genus are viable, the they do not produce viable gametes or ascospores in yeast resulting in reproductive isolation as a sterility barrier [9]. Hybridization of phenotypically diverse yeast has been exploited for the improvement of industrial strains for specific purposes.

Fermenting yeasts, specifically S. cerevisiae, has been unwittingly domesticated throughout humanity's existence via the production of various foods and beverages, including bread, beer, wine, and sake. One factor in S. cerevisiae selection is its unique metabolic capabilities as a Crabtree positive yeast; they amass ethanol in the presence of oxygen. The commonly preferred eukaryotic metabolic pathway in the presence of oxygen is oxidative respiration for its high ATP yield. But in the high concentrations of six-carbon carbohydrates, such as glucose, this pathway is repressed by the Crabtree effect. Under these conditions, the energy for growth comes from the glycolysis pathway until exhaustion of six-carbon molecules causes a diauxic shift to oxidation of the two-carbon ethanol molecules into $\mathrm{CO}_{2}[19,20]$. Crabtree positive microbes are beneficial in the production of alcoholic beverages which have been produced for at least 9000 years, and the earliest known recording of Japanese sake is mentioned ca. 285 AD in an ancient Chinese document called Gishiwajinden [21-23]. Sake is the alcoholic drink generated by fermenting rice and beer is that of barley, making their development specific to regions dominated by these grains. Rice and barley diverged 50 million years ago and rice was introduced to Japan from the Chinese Yangzi region around 400 BC, many differences exist between these two grains [24,25]. During the 15th century in Bavaria, lager-brewing arose [26] and is the most popular alcoholic beverage in the world today. Since the lager beer yeast, S. pastorianus was discovered to be a hybrid of $S$. eubayanus $\times$ S. cerevisiae, interest has sparked in the use of interspecific hybrids in fermentation [27]. Originally the S. eubayanus parent was identified in Patagonia and the question of lager yeast's origin has generated controversy [28-31]. Yeasts originated multiple times from various fungal lineages of which one gave rise to the budding yeasts [32]. The genomic diversity with geographical boundaries and many other lines of evidence support a Far East Asia origin for Saccharomyces [33-35].

Beer, wine, and sake are complex chemical matrixes resulting from many metabolic and chemical reactions in which raw ingredients determine initial sugar, assimilable nitrogen, and fatty acid profiles $[25,36]$. The volatile metabolic profile obtained during fermentation of different carbohydrates is reflective of the raw ingredients composition [37,38]. Wine is perhaps one of the oldest biotechnologies as yeast are often found on damaged grapes and crushing of the fruit facilitates the release of the fermentable sugars $[39,40]$. Obtaining fermentable sugars for beer and sake is quite different. Production of beer involves a saccharification of malted barley by the grain's own enzymes to convert their starches to maltose, glucose, and maltotriose found in descending concentrations. Boiling of the wort results in less than $3 \%$ of the malt lipids available to yeast during fermentation [41]. Fermentation of green beer is accomplished in 3 days to 10 days [42] and results in an average alcohol content of 5\% (vol/vol) with some brews tipping the scales around $10 \%$ (vol/vol) or more.

Immature sake is generally produced over 41 days and involves several steamed rice additions at temperatures between $12-20{ }^{\circ} \mathrm{C}$ applying high osmotic pressure on the yeast from the rice mash ratios [43]. The highest alcohol yield in the world, 17-20\% (vol/vol) without distillation, is obtained 
through this process [25]. Aspergillus oryzae, colloquially known as koji, is a keystone organism in the production of sake from polished rice [44]. By traditional Japanese sake mash methods, koji performs a continuous saccharification of highly milled rice starches to the fermentable sugars and the budding yeast, $S$. cerevisiae, ferments these sugars into ethanol [45]. Free sugars such as glucose and oligomers are produced by the koji enzymes glucoamylase and $\alpha$-amylase during the sake mash [23]. Recent work has shown that koji secretes mannitol 2-dehydrogenase which converts fructose to mannitol in the sake mash. Interestingly, S. arboricola efficiently catabolizes mannitol, an abundant natural energy storage molecule that Aspergillus sp. produce in high concentrations [46,47]. This phenotype is superior to $S$. cerevisiae metabolism of mannitol [14]. Considering the temperature tolerance and growth capabilities on mannitol, it was hypothesized that $S$. arboricola and interspecific hybrids are uniquely fit for sake fermentation with $A$. oryzae because of their metabolic access to the underutilized sugar-alcohol and temperature preference which affects the flavor active metabolites.

The aim of this study was to characterize the metabolic capabilities of S. arboricola and its hybrids with $S$. cerevisiae in Japanese rice wine. For the first time, sake fermentation profiling of $S$. arboricola and newly generated $S$. arboricola $\times$ S. cerevisiae interspecific hybrids is reported. The wine and beer brewing industries have often employed interspecific hybrids for their fermentations. S. kudriavzevii $\mathrm{x}$ S. cerevisiae are known to ferment wines, S. mikatae $x$ S. cerevisiae hybrids have been actively produced for wine, and the $S$. cerevisiae $x$ S. eubayanus hybrid produces the most popular beer in the world $[33,48,49]$. Limited research has been conducted on the metabolic capabilities of $S$. arboricola and these results suggest $S$. arboricola and the hybrids' propensity for fermentation may be suited for sake production.

\section{Materials and Methods}

\subsection{Yeast Strains}

Yeast strains of Sacharomyces cerevisiae included Italian wine isolate M22 [50], West African wine isolate DBVPG6044 [51], sake isolate Kyokai No. 7 known as haploid 868K7 [52], sake isolate TCR7 [53], American brewing isolate WLP001, and American brewing isolate HT01. Yeast strains of Saccharomyces arboricola included SA350 (syn. AS 2.3317), SA351 (syn. AS 2.3318), SA352 (syn. AS 2.3319 [14]. Hybrids SAM8c and SAM9a were between S. arboricola 350 x S. cerevisiae M22 (Table 1). A minimum of three biological replicates were used in each analysis.

Table 1. Yeast Strains Used During this Study.

\begin{tabular}{|c|c|c|c|}
\hline Strain & Species & Isolation Source & Reference \\
\hline SA350 (syn. AS 2.3317) & S. arboricola & Tree bark-China & Liti, G., et al. (2013) \\
\hline SA351 (syn. AS 2.3318) & S. arboricola & Tree bark-China & Liti, G., et al. (2013) \\
\hline SA352 (syn. AS 2.3319) & S. arboricola & Tree bark-China & Liti, G., et al. (2013) \\
\hline M22 & S. cerevisiae & Wine-Italy & Capece, A., et al. (2012) \\
\hline DBVPG6044 & S. cerevisiae & Billi wine-West Africa & Song, G., et al. (2015) \\
\hline $\begin{array}{c}\text { Kyokai No. } 7 \\
\text { (syn. 868K7/ K7) }\end{array}$ & S. cerevisiae & Sake-Japan & Katou, T., et. al. (2008) \\
\hline TCR7 & S. cerevisiae & Sake-Japan & Horie, K., et al. (2010) \\
\hline WLP001 & S. cerevisiae & Beer, American ale & $\begin{array}{l}\text { Commercially available } \\
\text { from White Labs, USA }\end{array}$ \\
\hline HT01 & S. cerevisiae & Beer, American ale & Current study \\
\hline SAM8c & $\begin{array}{l}\text { Hybrid (S. arboricola } x \\
\text { S. cerevisiae) }\end{array}$ & $\begin{array}{l}\text { Lab, spore to } \\
\text { spore mating }\end{array}$ & Current study \\
\hline SAM9a & $\begin{array}{l}\text { Hybrid (S. arboricola } x \\
\text { S. cerevisiae) }\end{array}$ & $\begin{array}{l}\text { Lab, spore to } \\
\text { spore mating }\end{array}$ & Current study \\
\hline
\end{tabular}




\subsection{Yeast Isolation}

Saccharomyces cerevisiae HT01 was the only strain isolated for this study and was isolated as described previously [54] with slight modification. Briefly, beer was harvested from a can sanitized on the outside with $70 \%$ ethanol into an enrichment media ( $3 \mathrm{~g}$ yeast extract, $3 \mathrm{~g}$ malt extract, $5 \mathrm{~g}$ peptone, $10 \mathrm{~g}$ sucrose, $76 \mathrm{~mL}$ EtOH, $1 \mathrm{mg}$ chloramphenicol, and $1 \mathrm{~mL}$ of $1-\mathrm{M} \mathrm{HCl}$ per liter). Samples were transferred to sterile tubes and incubated until signs of yeast appeared. Cultures were then streaked onto YPD media and single colonies were grown and stocked. From these stocks, the yeast culture's genomic DNA was extracted, the ITS region was amplified via polymerase chain reaction (PCR) [55], Sanger sequenced at the West Virginia University Genomic Core, and the isolated yeast was confirmed to be $S$. cerevisiae via utilizing NCBI Blast.

\subsection{Serial Spot Dilutions}

Serial spot dilution growth assays were conducted as described previously [56] with some modification. Briefly, $\mathrm{OD}_{600 \mathrm{~nm}}$ growth readings were taken from fresh, overnight cultures of each yeast grown at $23^{\circ} \mathrm{C}$. For each yeast assayed, a total of $3.2 \times 10^{5}$ yeast cells were transferred to a well in the first column of a 96 well plate. Each yeast assayed was serially diluted 4 times in a 1:10 ratio, using sterile distilled and MilliQ (MQ) filtered water, across the rows which resulted in 5 wells each. A handheld 48 pin plate was used to place the serial dilution spots onto solid YPD agar media. Plates were then incubated at $4{ }^{\circ} \mathrm{C}$ for ten days, $10^{\circ} \mathrm{C}$ for seven days, and $15^{\circ} \mathrm{C}$ for four days. Growth was assessed and photographed.

\subsection{Sporulation and Spore Staining}

Fresh liquid yeast cultures were grown in YPD (1\% yeast extract, $2 \%$ peptone, $2 \%$ dextrose) overnight at $23{ }^{\circ} \mathrm{C}$ in a shaking water bath. Isolates were streaked out onto YEP(EG) buffered agar plates ( $1 \%$ succinic acid, $1 \%$ yeast extract, $2 \%$ peptone, $2 \%$ glycerol, $2 \%$ agar, potassium hydroxide to pH 5.5, 2.5\% ethanol) for 2-3 days. Single colonies were thinly patched onto Snack-Spo Zn agar plates ( $1 \%$ potassium acetate, $0.1 \%$ yeast extract, $0.05 \%$ dextrose, $0.005 \%$ zinc acetate, $2 \%$ agar) and incubated for 6 days. To measure spore formation, a modified Schaeffer-Fulton endospore staining technique was used. Briefly, cultures from the sporulation plates were suspended in $1 \mathrm{ml}$ distilled water and recovered by pipette. The suspended culture was fixed to a glass microscope slide via flame. Malachite green $(10 \%, 0.1 \mathrm{~g} / \mathrm{mL})$ was then used to stain the spore walls for $15 \mathrm{~min}$ (minute/s) before decoloring and rinsing with water. Safranin $(0.25 \%, 2.5 \mathrm{mg} / \mathrm{mL})$ was used as a counterstain for non-sporulated cells for $1 \mathrm{~min}$ before rinsing with water and mounting in glycerol. Malachite green cells were counted as spores and safarin red cells were counted as non-sporulated yeast cells [57]. Images were taken under a light microscope and sporulation efficiency for each strain was calculated, reported in the results section, to select the best possibility of a successful hybridization.

\subsection{Interspecific Hybridization}

The ascus of the spore was digested over $1 \mathrm{hr}$. with Zymolase $(25 \mathrm{mg} / \mathrm{mL})$ at $37^{\circ} \mathrm{C}$. The digested spores were placed dropwise on YPD agar at an angle to facilitate a central streak of liquid across the plate. Micromanipulation of spores from S. arboricola strain 350 and S. cerevisiae M22 spores was performed by fiber optic needle under a light microscope using the SporePlay (Singer Instruments, Roadwater, England) dissection microscope by Singer Instruments and yielded 40 spore to spore mattings. Visual observations were conducted on the shmooing process during incubation at $25^{\circ} \mathrm{C}$. Single colonies were selected, streaked out for purification, and stocked at $-80{ }^{\circ} \mathrm{C}$ with cryogenic media ( $1 \%$ yeast extract, $2 \%$ peptone, $15 \%$ glycerol). 


\subsection{Genomic DNA Extraction}

Alkaline lysis genomic DNA extraction was performed on fresh, overnight cultures by harvesting $\left(0.3 \times 10^{7}\right)$ cells via cold centrifugation at $7500 \times g$ for $3 \mathrm{~min}$. Cells were washed twice with phosphate-buffered solution (PBS) before $\mathrm{NaOH}(0.02 \mathrm{M})$ addition and subsequent incubation at $100{ }^{\circ} \mathrm{C}$ for $10 \mathrm{~min}$. The cellular solution underwent cold centrifugation at $4{ }^{\circ} \mathrm{C}$ for $3 \mathrm{~min}$ before $250 \mu \mathrm{L}$ of supernatant was mixed with $50 \mu \mathrm{L}$ acetic acid $(2.5 \mathrm{M})$ and then $300 \mu \mathrm{L}$ of 2-propanol. Cold centrifugation was performed again for $15 \mathrm{~min}$ before the supernatant was discarded. Ethanol $(80 \% \mathrm{v} / \mathrm{v})$ was added to the DNA pellet to lightly mix the solution before a 5 min cold centrifugation. The DNA was dried at room temperature and resuspended in TE buffer.

\subsection{Polymerase Chain Reaction}

DNA concentrations were measured by $\mathrm{OD}_{260 \mathrm{~nm}}$ via a glass black cell cuvette. PCR confirmed S. arboricola 350 and S. cerevisiae M22 (SAM hybrids) interspecific hybridization. Two multiplexed species-specific primer sets were used, detailed previously [58]. The oligonucleotide sequences used for primers were as follows; for S. arboricola sarbF1 (GGC ACG CCC TTA CAG CAG CAA TCG) and sarbR2 (TCG TCG TAC AGA TGC TGG TAG GGC GCT); for S. cerevisiae scerF2 (GCG CTT TAC ATT CAG ATC CCG AG) and scerR2 (TAA GTT GGT TGT CAG CAA GAT TG ATC). A master mix for the PCR reactions was made on ice and consisted of PCR reagents from kit: KOD-Plus-Neo (product code KOD-401) ordered from TOYOBO, Japan. The PCR Touchdown [59] thermocycle protocol was used. During gel electrophoresis [60], the S. cerevisiae band generated at 150bp (base pairs) and S. arboricola generated at $349 \mathrm{bp}$.

\subsection{Sake Fermentations}

Freshly grown cells $\left(2.0 \times 10^{9}\right)$ were measured by $\mathrm{OD}_{600 \mathrm{~nm}}$, harvested from YPD via centrifugation at $3200 \times g$ for $3 \mathrm{~min}$, and washed in MilliQ water twice. The harvested yeast, rice, koji, lactate, and water were mixed together in mason jars covered with loose lids. Incubation occurred at $15{ }^{\circ} \mathrm{C}$ for 2 weeks with an initial remixing of the mash occurring after the first $24 \mathrm{~h}$. Fermentation was monitored daily by mass reduction of the sake mash, which corresponded to $\mathrm{CO}_{2}$ production. Fermentation trials were performed in triplicate. Post-fermentation, the sake mash was harvested into conical tubes by centrifuged at $4{ }^{\circ} \mathrm{C}$ and $3200 \times g$. The supernatant was transferred to storage at $4{ }^{\circ} \mathrm{C}$ for further analysis. Statistical analysis of ethanol content was validated by one-way ANOVA with a two-tailed student's $t$-test post-hoc analysis and ordered difference report for each day of fermentation.

\subsection{Chromatography Analysis}

\subsubsection{Gas Chromatography-Flame Ionization Detection}

For gas chromatography-flame ionization detection (GC-FID) of the sake supernatant, ribitol (syn. adonitol) $(0.2 \mathrm{mg} / \mathrm{mL})$ was supplied as an internal standard. Samples were freeze-dried via liquid nitrogen bath followed by vacuum chamber drying for $6 \mathrm{~h}$. The freeze-dried samples were mixed with $100 \mu \mathrm{L}$ of methoxylamine diluted with pyridine $(20 \mathrm{mg} / \mathrm{mL}]$ and incubated at $30^{\circ} \mathrm{C}$ for $90 \mathrm{~min}$ with agitation (1500 rpm). The sample was mixed with $50 \mu \mathrm{L}$ of N-methyl-N-TMS-trifluoroacetamide (MSTFA) incubated for $30 \mathrm{~min}$ at $37^{\circ} \mathrm{C}$ with agitation and transferred into a glass vial for chromatography metabolome analysis. A Cp-sil8CB column from Agilent, model \#CP8751 (30 mm, $0.25 \mathrm{~mm}, 0.25 \mu \mathrm{m}$ ) was used to assess the sake fermentation samples. The injection was at $230{ }^{\circ} \mathrm{C}$ with a $1 \mathrm{~mL} / \mathrm{min}$ helium carrier gas flow rate. The column temperature was held at $80^{\circ} \mathrm{C}$ for $2 \mathrm{~min}$ before rising $10^{\circ} \mathrm{C} / \mathrm{min}$ until $320^{\circ} \mathrm{C}$ was achieved, the temperature was held for $12 \mathrm{~min}$ before reaching a $320^{\circ} \mathrm{C}$ detector. The Shimadzu Corporation (Shimadzu Manufacturing Company, Kyoto, Japan) model GC-2014AFSC $100 \mathrm{~V}$ was used in performing the GC-FID analysis. 


\subsubsection{Head Space-Solid Phase Microextraction}

For the head space-solid phase microextraction (HS-SPME), the sake supernatant samples were prepared with $\mathrm{NaCl}$ and methyl hexanoate $(40 \mathrm{mg} / 100 \mathrm{~mL})$ was supplied as an internal standard. In a glass vial, the solution was agitated under $80^{\circ} \mathrm{C}$ heat with a stir bar $(160 \mathrm{rpm})$ for $15 \mathrm{~min}$. A syringe was inserted into the vial to expose a SPME fiber (100 $\mu \mathrm{m}$ PDMS) for $15 \mathrm{~min}$. The fiber was retracted into the syringe before removal from the vial and inserted into the injector for a 5 min exposure. A DB wax column from Agilent, model \#122-7032 $(30 \mathrm{~mm}, 0.25 \mathrm{~mm}, 0.25 \mu \mathrm{m})$ was used. The injection was at $200{ }^{\circ} \mathrm{C}$ with a $0.95 \mathrm{~mL} / \mathrm{min}$ helium carrier gas flow rate. The column temperature was held at $60^{\circ} \mathrm{C}$ for $1 \mathrm{~min}$ before rising $3^{\circ} \mathrm{C} / \mathrm{min}$ until $100^{\circ} \mathrm{C}$ was achieved, the rate increased to $15^{\circ} \mathrm{C} /$ min until $200^{\circ} \mathrm{C}$ was reached and held for $4 \mathrm{~min}$ before reaching a $320^{\circ} \mathrm{C}$ detector. The Shimadzu Corporation (Shimadzu Manufacturing Company, Kyoto, Japan) model GC-2014AFSC $100 \mathrm{~V}$ was used in performing the HS-SPME analysis.

\subsubsection{Gas Chromatography-Mass Spectroscopy}

For gas chromatography-mass spectroscopy (GC-MS) of endogenous metabolites, stationary phase yeast cultures were grown in YPD liquid media. Stationary phase was defined at an $\mathrm{OD}_{600 \mathrm{~nm}}$ of 2.0. Cells $\left(4 \times 10^{7}\right)$ were harvested, washed, and freeze-dried. An extraction solution (chloroform:methanol:MQ [2:5:2]) with ribitol $(0.2 \mathrm{mg} / \mathrm{mL})$ as the internal standard was added to the freeze-dried samples and incubated for $30 \mathrm{~min}$ at $37^{\circ} \mathrm{C}$ under agitation (1500 rpm). The samples were centrifuged, and the supernatant was harvested. MQ water was added to the supernatant and centrifuged. The supernatant was concentrated under vacuum centrifugation $(-100 \mathrm{kPa})$ at $37^{\circ} \mathrm{C}$. MQ water was added, and the water-soluble metabolites were freeze-dried. Methoxyamine $(20 \mathrm{mg} / \mathrm{mL})$ was added to the samples and incubated for $90 \mathrm{~min}$ at $30^{\circ} \mathrm{C}$ under agitation (1500 rpm). MSTFA ( $N$-methyl- $N$-trimethylsilyl trifluoroacetoamide) was added to the samples and incubated for $30 \mathrm{~min}$ at $37^{\circ} \mathrm{C}$ with agitation (1500 rpm). Samples were supplied in glass vials for GC-MS analysis using an Agilent DB-5MS+DG ( $30 \mathrm{~m}, 0.25 \mathrm{~mm}, 0.25 \mathrm{um}$ ) column, splitless injection, and helium carrier gas $(1 \mathrm{~mL} / \mathrm{min})$. The column temperature rose from $80^{\circ} \mathrm{C}$ at a rate of $13{ }^{\circ} \mathrm{C} / \mathrm{min}$ until reaching a $320^{\circ} \mathrm{C}$ detector. The Agilent Technologies, Inc. (Agilent Technologies, Santa Clara, California, United States of America) model 7890 B was used for the GC system, model 5977 A was used for the MS system, and the National Institute for Standards and Technology (NIST) mass spectral library (United States Department of Commerce, Gaithersburg, MD, USA) was used.

\subsubsection{Data Analysis}

The peak area of identified compounds was divided by the peak area of the internal standard for normalization of the data. Normalized peak areas of the compounds and ethanol concentrations measured during sake fermentations were auto-scaled and used as independent variables in the loading plots for construction of the principal component analysis (PCA). Statistical analysis was performed by soft independent modeling by class analogy (SIMCA) methodology by SIMCA version 13.0.3.0 (Umetrics, Umeå, Sweden) computer software. Analysis of variance (ANOVA), post-hoc students t-test, and post hoc Tukey-Kramer honest significance test (Tukey HSD), $p<0.05$ was used for statistical significance. Deviations from this statistical analysis procedure, if occurred, was reported in individual results or methods sections. Heatmap was generated through MetaboAnalyst 4.0 [61]. Heatmaps were based on data normalization by internal reference feature, cubed root transformation, pareto/range data scaling for endogenous/sake metabolites, clustering by Ward's method, and Euclidean distance measurements. 


\section{Results}

Endogenous metabolome characterization of S. arboricola was put in context of industrially relevant S. cerevisiae yeast. Two yeast strains were chosen to represent either beer, wine, or sake fermentation industries. WLP001 and HT01 represented beer, M22 and DBVPG6044 represented wine, K7 and TCR7 represented sake production. SA350, SA351, and SA352 were used to represent wild S. arboricola (Table 1). Endogenous metabolite profiling was visualized in a hierarchical clustering heatmap that showed clustering of yeast by industry and species (Figure 1A). Ward's linkage clustering algorithm created two main clusters separated by species with the exception of West African bili wine strain DBVPG6044 that grouped within S. arboricola. The yeast in this cluster, located in the right half of the heatmap, all showed a low concentration of endogenous amino acids. Beer strains, sake strains, and wine strain M22 composed the other cluster on the left half. Beer strains paired together, and sake strains paired together with Italian wine strain M22. These industrial strains had similar but varying metabolic profiles displaying high endogenous levels of many amino and organic acids.
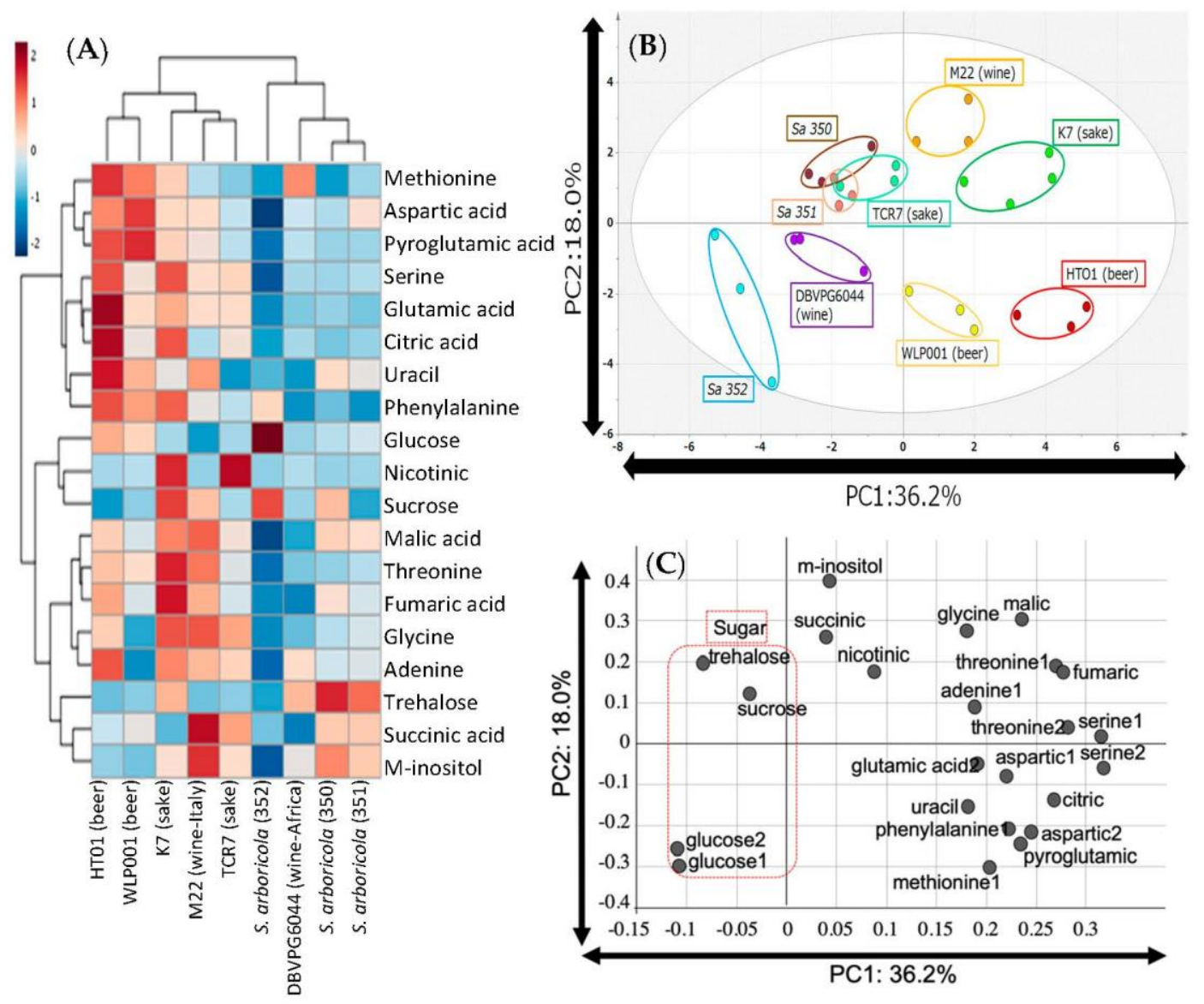

Figure 1. Yeasts endogenous metabolic profiles. (A) Hierarchical clustering heatmap of endogenous metabolite profiles between strains and species. Relatively high compound concentrations were shown in varying degrees of red. Relatively low compound concentrations were shown in varying degrees of blue. Shown as average concentration per sample groupings of three replicates. (B) Principal component analysis (PCA) score plot of Saccharomyces yeast explaining $17.4 \%$ of the variance on PC2 and $31.6 \%$ of the variance on PC1. (C) PCA loading plot. Saccharide content is circled to show importance in the PC1 variance. PCA and loading plot generated through SIMCA analysis. Three replicates were used for each strain. 
A score plot generated through principal component analysis separated the strains into general industry-specific groups (Figure 1B). A total of 19 metabolites identified by GC-MS were used as variables in the construction of the loading plot (Figure 1C). Sugar utilization played a major role in separation of the strains. S. arboricola strains were grouped to the left while beer and sake strains grouped opposite to the right on principal component (PC1) explaining $36.2 \%$ of the sample variance and separating the groups by species. On the axis of PC2, sake yeast grouped high, wine yeasts were neutral/variable, and beer yeasts were low explaining $18.0 \%$ of sample variance and separating the yeast by their industrial niche domestication. Glucose, sucrose, and trehalose negatively contributed to PC1, which exemplified sugar uptake differences and was inferred to translate to fermentation aptitude. Beer brewing strains were found to be the most inclined yeasts in this regard and S. arboricola were found to be the least adept. A third component, explaining 12.7\% was used to create a 3D PCA plot of the endogenous metabolites (Figure S1). Citric acid, malic acid, fumaric acid, glutamic acid, nicotinic acid, succinic acid, aspartic acid, threonine, serine, glycine, phenylalanine, pyroglutamine, methionine, uracil, inositol, and adenine positively contributed to PC1. A loading matrix was constructed for the variables (Table S1). Glycine, threonine, malic acid, fumaric acid, nicotinic acid, succinic acid, sucrose, trehalose, inositol, and adenine positively contributed to PC2. Phenylalanine, pyroglutamine, methionine, uracil, aspartic acid, and glucose contributed negatively to PC2, which distinguished the beer brewing strains from the sake strains. These two groups are represented in the heatmap's industrial cluster. Factors from the heatmap show the difference between sake and beer yeast include the endogenous inositol levels; which were high in sake yeast and affect membrane fluidity during osmotic stress such as an industrial sake mash.

The potential of Saccharomyces hybridization to broaden metabolic capabilities and sensory complexity from volatile metabolites was explored using S. arboricola and S. cerevisiae. Sporulation efficiency was used in selection of strains for direct-mating hybridization as industrial strains are typically poor sporulators. S. arboricola 350 and S. cerevisiae M22 yielded the highest sporulation efficiency at $69 \%$ and $91 \%$ respectively (Figure S2A). Selection of the S. cerevisiae industrial strain relied on sporulation results to optimize spore-spore mattings and given M22 grouped similar to the sake strain metabolism in Figure 1B, M22 was choosen. Other S. arboricola strains sporulated at $68 \%$ for 351 and 20\% for 352. Interspecific SAM (S. arboricola 350 and S. cerevisiae M22) hybrids, SAM8c and SAM9a, generated double bands representing genomic input from both species. Two spore-to-spore mating colonies were advanced to lab-scale sake fermentation after confirmation of hybrid state by species-specific multiplexed PCR (Figure S2B). Cryotolerance of S. arboricola and the hybrids was shown as substantial growth at 4 and $10^{\circ} \mathrm{C}$ after ten and seven days, respectively (Figure 2). At $15{ }^{\circ} \mathrm{C}$, there was no perceivable difference between yeast growth. Thermosensitivity was not detected using the serial spotting dilution assay in temperatures up to $30{ }^{\circ} \mathrm{C}$, slow growth of $S$. arboricola cultures during extreme temperature highs in the summer months was observed.

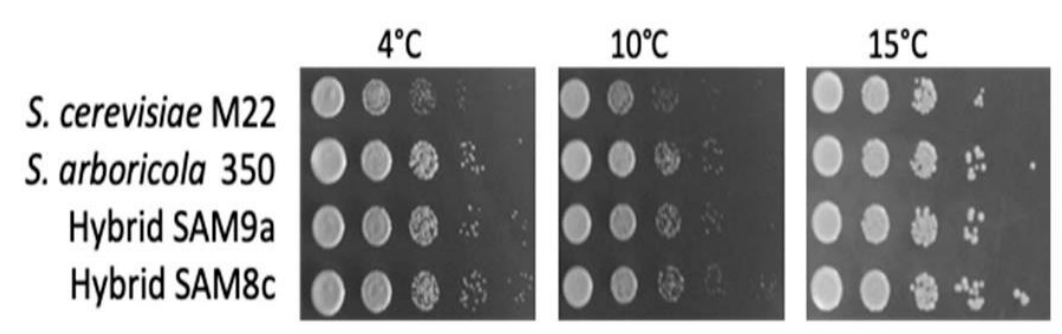

Figure 2. Cryotolerance of parental and hybrid yeasts. Serial spot dilution growth assay of parental S. cerevisiae M22, parental S. arboricola 350, and the SAM hybrids. Three different temperatures of $4{ }^{\circ} \mathrm{C}$, $10^{\circ} \mathrm{C}$, and $15^{\circ} \mathrm{C}$ was used in assessment of their cryotolerance. Yeast were incubated on solid YPD agar for ten days at $4{ }^{\circ} \mathrm{C}$, seven days at $10{ }^{\circ} \mathrm{C}$, and four days at $15^{\circ} \mathrm{C}$. 
To determine if important sake flavor molecules changed with hybridization, ethyl hexanoate, isoamyl acetate, and ethanol fermentation was measured. In fact, it was found that $S$ arboricola, $S$. cerevisiae, and the hybrids metabolite profiles after lab-scale sake mash fermentation trials were different. The hybrids had a more vigorous fermentation, yielding a higher alcohol content than S. cerevisiae by day seven ( $p=0.031$ ) of the 14 day trial fermentation (Figure 3A). A one-way ANOVA with a two-tailed student's t-test post-hoc analysis and ordered difference report for each day of fermentation was generated in determine ethanol content significance (Table S2). The gap between fermentation rates declined over time trending towards non-significance between all samples if more time was allotted. The fermentations were stopped as the fermentation rate slowed down and a fair amount of ethanol 10\%+ was produced. The fermentation trials were designed with time constraints as this is often a major factor in production settings and attenuation was secondary. The final alcohol yield at day 14 was significant between $S$. cerevisiae and the hybrids $(p=0.038)$, while $S$. arboricola was not significantly different than either hybrid nor S. cerevisiae. Hybrid SAM9a had the most productive fermentation rate, followed by hybrid SAM8c, S. arboricola 350, and S. cerevisiae M22. The mean final alcohol content of sake produced was $12.92 \%$ for the hybrids, $12.15 \%$ for S. arboricola 350 , and $11.46 \%$ for S. cerevisiae M22.

Detection of volatile aromatic compounds allows insight into flavor and sensory attributes of the final sake produced and HS-SPME technology in the gas chromatography system was utilized. Sake fermented with $S$. arboricola contained significantly less ethyl hexanoate (syn. ethyl caproate) $\left(0.207 \mathrm{mg} \mathrm{mL}^{-1}\right.$, st error 0.016$)$ than S. cerevisiae $\left(0.316 \mathrm{mg} \mathrm{mL}^{-1}\right.$, st error $\left.0.019, p=0.005\right)$, or the hybrids $\left(0.308 \mathrm{mg} \mathrm{mL}^{-1}\right.$, st error $\left.0.014, p=0.003\right)$ (Figure 3B). Sake fermented by $S$. arboricola contained a concentration of isoamyl acetate $\left(0.368 \mathrm{mg} \mathrm{mL}^{-1}\right.$, st error 0.064$)$ that was high compared to $S$. cerevisiae $\left(0.259 \mathrm{mg} \mathrm{mL}^{-1}\right.$, st error $\left.0.064, p=0.25\right)$ and the hybrids $\left(0.252 \mathrm{mg} \mathrm{mL}^{-1}\right.$, st error $\left.0.045, p=0.17\right)$, but fell short of a significant $p$-value (Figure 3C). Ethyl hexanoate imparts apple or aniseed and isoamyl acetate imparts a banana-like attribute to human sensory receptors. Whole metabolite heatmap by sample was created showing a separation of $S$. arboricola from the hybrids and M22 individual samples when volatile compounds were used (Figure S3A) or a separation of all three when non-volatile metabolites were used (Figure S3B).

Sake fermentation profiles were visualized in a hierarchical clustering heatmap with hybrids clustering in closer proximity to the S. arboricola yeast (Figure 4A). Parental strain S. cerevisiae M22's sake metabolite profile contained high amounts of glucose, malic acid, threonine, and valine while parental S. arboricola's profile contained high amounts of citric acid, aspartic acid, glutamic acid, leucine, isoleucine, alanine, phenylalanine, inositol, and glycerol. Parental profiles almost completely opposed one another with only serine, succinic acid, and urea showing similar parental concentrations. M22 was the most distant parent to the hybrids' profile. The heatmap of the hybrid strains showed a mosaic blending of the two parental species. Metabolomic analysis using principal components clearly separated interspecific hybrids from each parent based in a PCA score plot (Figure 4B). A total of 20 metabolites, including 17 non-volatile compounds, were identified by GC-FID and 3 volatile compounds identified by HS-SPME These were used as variables in construction of the loading plot (Figure 4C). Principal component (PC1) separated samples by their species and explained $43.2 \%$ of the variance between the samples. Fermentation profiles showed a separation of the two Saccharomyces species on opposite ends of PC1 and the hybrid yeast grouped to the middle. PC2 separated the hybrid from the parental samples by the novel hybrid fermentation features that explained $23.1 \%$ of the sample variance. Threonine, valine, malic acid, glucose, ethyl hexanoate, and dimethyl trisulfur (DMTS) positively contributed to PC1. Phenylalanine, isoleucine, leucine, alanine, aspartic acid, citric acid, glutamic acid, succinic acid, inositol, glycerol, ethanol, and isoamyl acetate were amino acids, organic acids, and other molecules that negatively contributed to PC1. Ethanol, DMTS, phenylalanine, ethyl hexanoate, glycerol, isoleucine, glutamic acid, valine, and threonine negatively contributed to PC2. Serine, succinic acid, malic acid, glucose, urea, isoamyl acetate, aspartic acid, inositol, and alanine positively contributed to PC2. A loading matrix was constructed for the variables (Table S3). 


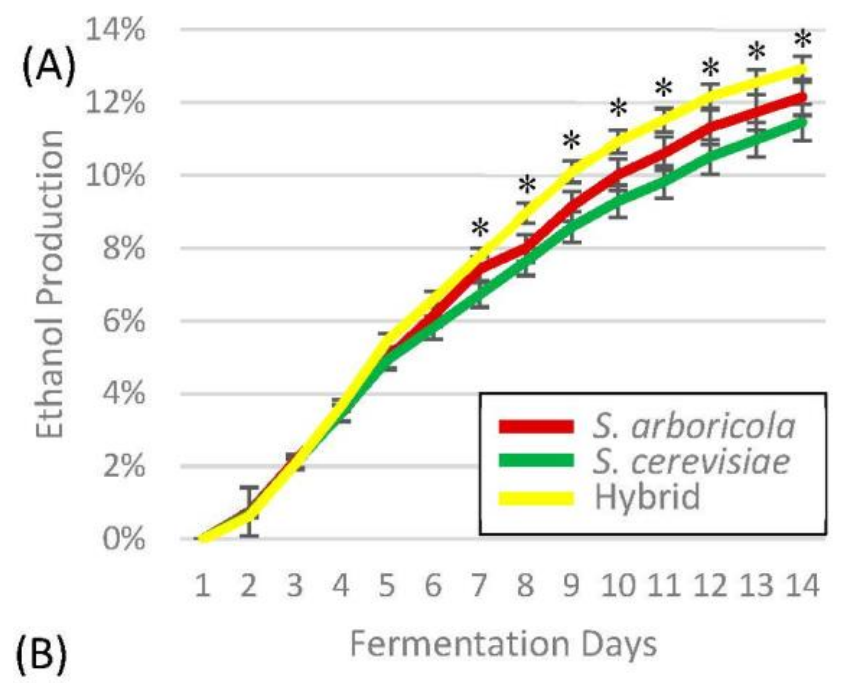

(B)
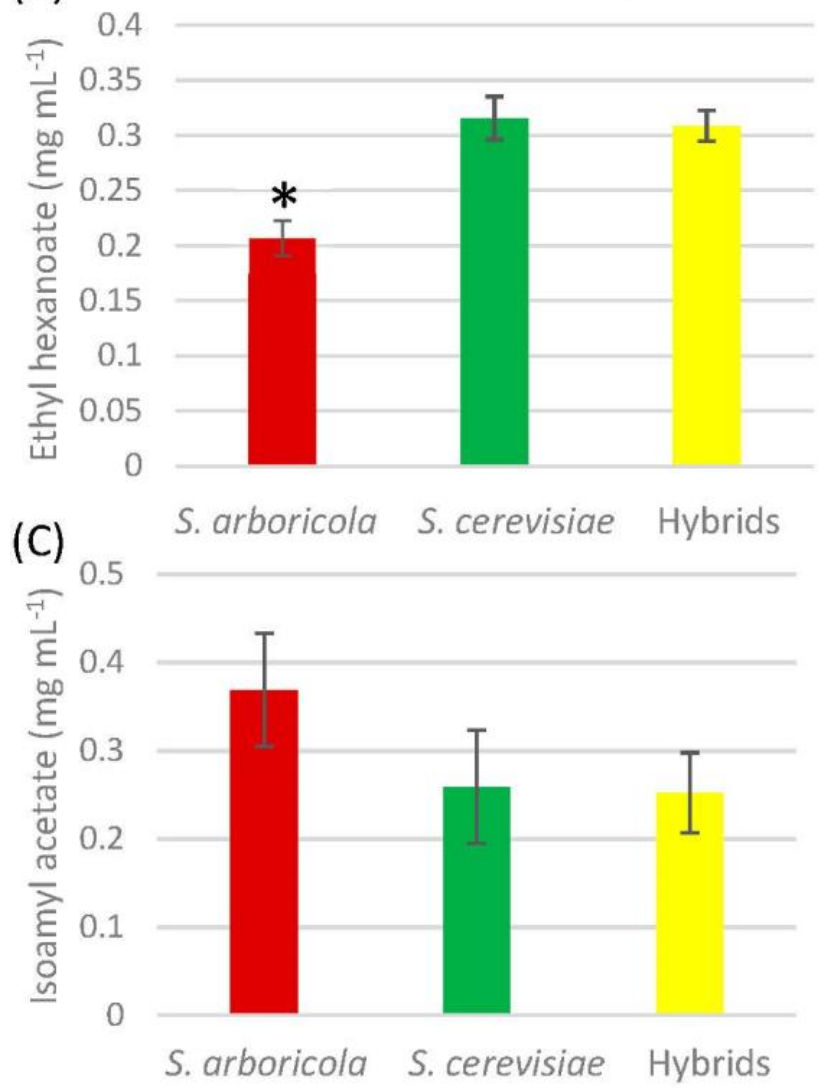

Figure 3. Phenotypic characteristics of hybrids and parental yeast. (A) Mean alcoholic fermentation rates of S. arboricola 350, S. cerevisiae M22, and the SAM hybrids are shown as a line graph representing the alcohol content over 14 days in time. Standard error bars shown in line graph (B) Bar chart depicting the production of ethyl hexanoate in $\mathrm{mg} \mathrm{mL}^{-1}$. (C) Bar chart depicting the production of isoamyl acetate in $\mathrm{mg} \mathrm{mL}^{-1}$. Statistical analysis performed by ANOVA, post-hoc students $t$-test, and post-hoc Tukey-HSD, $p<0.05$. 

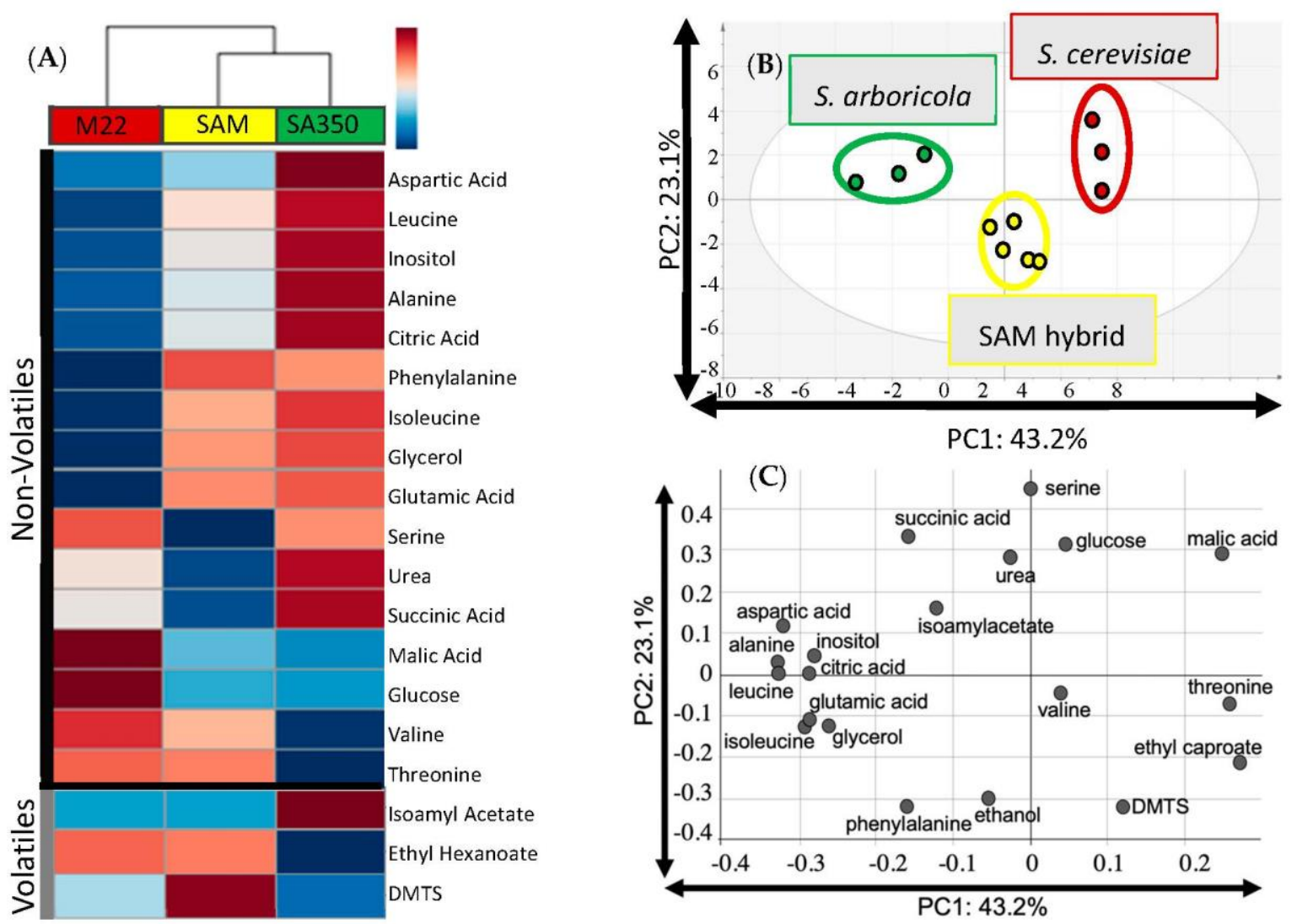

Figure 4. Sake fermentation profiles of S. arboricola interspecific hybrids and parental strains. (A) Hierarchical clustering heatmap of sake fermentation profiles between strains and species. Relatively high compound concentrations were shown in varying degrees of red. Relatively low compound concentrations were shown in varying degrees of blue. Shown as average concentration per sample groupings of three replicates each. (B) PCA score plot of sake fermentation profiles obtained for S. cerevisiae, S. arboricola, and the SAM hybrids. (C) PCA loading plot of sake fermentation profiles obtained for S. cerevisiae, S. arboricola, and the SAM hybrids. PC1 explained $43.2 \%$ and PC2 explained $23.1 \%$ of sample variance. PCA and loading plot generated through SIMCA analysis. Three replicates were used for each strain.

\section{Discussion}

This is the first report of sake brewing by Saccharomyces arboricola and its hybrids. The exploratory metabolic analysis of S. arboricola, a neglected Saccharomyces yeast lacking metabolic evaluation, adds to the novelty of this study. Through direct mating of S. arboricola to S. cerevisiae, interspecific hybrids gained a higher final ethanol content over S. cerevisiae and a higher ethyl hexanoate over S. arboricola. It was found that the low levels of endogenous amino/organic acids clustered S. arboricola apart from the industrial strains by principal component analysis and hierarchical clustering heatmapping. In sake fermentations, hybrid strains showed a mosaic profile of parental strains except where parental profiles were similar. This metabolic analysis suggested S. arboricola had higher transportation activity of pyruvate to the mitochondria and a lower amino acid net uptake than S. cerevisiae. Additionally, hybrid metabolic analysis suggested an increase in ethanolic fermentation from pyruvate and increased sulfur metabolism. Together, these results suggest $S$. arboricola is poised for in-depth and focused metabolomic exploration.

Endogenous metabolite comparison of nine industrially relevant and diverse yeast by GC-MS provided a separation of metabolomic profiles where industry and species appeared to be drivers of distinction in both heat map clustering and PCA. The internal composition is characteristic of their metabolic tendencies and influences the environment in which many endogenous metabolic 
reactions occur. Of the industrial yeast, sake yeast separated from beer yeast by PC2 of the PCA (Figure 1B) which is characterized by the glucose to fructose ratio, inositol level, as well as the organic and amino acid profile. The endogenous inositol levels were high in sake yeast and affect membrane fluidity during osmotic stress such as an industrial sake mash. Sugar utilization played a major role in separation of the strains as evident in the loading plot which highlighted the importance of sugar metabolism. Metabolic distinctions between the glucose to fructose ratio of beer to sake or wine yeasts can be inferred to resemble the kinetic differences of hexokinase-mediated sugar phosphorylation. The glucose to fructose ratio between wine strains was correlated with the kinetics of hexokinase-mediated sugar phosphorylation and the inherent properties of each unique strain [62,63]. High amounts of endogenous inositol and trehalose were characteristic of S. arboricola. Furthermore, serine and glycine were found to be low in the $S$. arboricola cluster and are important glycolytic metabolites biosynthesized from 3-phosphoglycerate or alternatively through the gluconeogenic pathway utilizing glyoxylate [64]. Organic and amino acid metabolism shift between alternative biosynthesis pathways and their byproducts likely play a role in the difference seen between strains. Additional genetic and environmental factors are also suspected to play a role in strain metabolomic profiles as seen by increased copy number of $M A L$ (maltose) genes in sake and beer yeast, yet wine strains tend to lose this attribute because their typical industrial fermentation sugar availability lacks maltose [65]. Copy number variations (CNV) are concentrated in the sub telomeric regions, with chr. I, VII, VIII, IX, X, XII, XV, and XVI being more susceptible to variation [65]. Gene ontology related to carbon and nitrogen metabolism, ion transport, and flocculation are prone to CNV [66,67] which often results in deletions rather than amplifications of genetic material [65]. The CNVs are thought to underline niche adaptation and domestication $[65,66]$.

Flavor-active elements formed during yeast fermentation can be divided into five key groups: sulfur-containing molecules, organic acids, higher alcohols, carbonyl compounds, and volatile esters [68-71]. Of these classifications, volatile esters are the largest and are responsible for the highly desired fruity character in several alcoholic beverages [72]. Production of ethyl hexanoate and isoamyl alcohol is maximized during fermentations at $15^{\circ} \mathrm{C}[73,74]$. Ethyl hexanoate imparts apple or aniseed and isoamyl acetate imparts a banana-like attribute to human sensory receptors. Ethyl hexanoate, a MCFA (medium chain fatty acids) ester with a $0.17-0.21 \mathrm{mg} \mathrm{mL}^{-1}$ flavor threshold, is an important flavor molecule for ginjo sake [68,75]. The fruity ester, formed from hexanoic acid or hexanoyl CoA with ethanol, imparts a light, sweet, apple complexity to the delicate and fragrant beverage. Ginjo sake is produced from rice with the outer $40 \%$ of the grain polished away to remove the hull, bran, and part of the starchy endosperm, leaving $60 \%$ of the rice to create the sake mash. During the sake fermentation trials, S. arboricola produced significantly less ethyl hexanoate than either the hybrid or S. cerevisiae wine strain M22. Increased inositol concentrations have been shown to decrease production of ethyl hexanoate during fermentation [76]. This relationship was seen in PC1 of the hybrids and suggests $S$. arboricola's inositol biosynthesis pathway is more active, in turn producing low ethyl hexanoate levels seen in this study. Additionally, S. arboricola's production of isoamyl acetate showed a trend towards a significant increase over the hybrid or S. cerevisiae M22 (Figure 3C). Isoamyl acetate, an acetate ester with a $0.6-1.2 \mathrm{mg} \mathrm{mL}^{-1}$ flavor threshold, imparts a distinct banana character typical of hefeweizen yeast [68]. Hybrid strains produced a pleasant aromatic profile containing both ethyl hexanoate and isoamyl acetate. Ethanol hexanoyl transferase, Eht1, is believed to catalyze the formation of ethyl hexanoate [68]. Alcohol acetyltransferase genes Atf1 and Atf2 are responsible for the total biosynthesis of isoamyl alcohol and divergence in the Atf proteins has been suggested to influence the whole ester aroma profile of yeast strains [72]. Protein identity between S. arboricola and S. cerevisiae for Atf1 was 81\%, Atf 2 was 36\%, and Eht1 was 84\%. Together the aromatic ester profile of S. arboricola was unique in the combination of low ethyl hexanoate and isoamyl alcohol concentrations are speculated to be owing from inositol lipid activity and variation in factors affecting Atf activity. This area of research is merits further investigation. 
Interspecific hybrids are commonly employed in agricultural and horticultural settings where hybrid vigor provides an increased or transgressive phenotype [77]. In oenology Saccharomyces hybrids, such as S. cerevisiae $\times$ S. kudrazevii, are often employed [78,79]. Many times Saccharomyces hybrids are able to yield more ethanol during fermentation under lab controlled environments [80], and these results support previous findings. The use of $S$. arboricola in sake production is novel and no other study had S. arboricola's metabolism as the primary focus of the manuscript. To date several labs have investigated Saccharomyces hybrids, one study included S. arboricola in a beer brewing context while one other included S. arboricola among their hybrids in a biofuel context $[80,81]$. This research showed that in a sake mash, SAM interspecific hybrids produced a more vigorous fermentation in a short amount of time which may be beneficial if used or further developed in a production context. Of the range of temperatures for Saccharomyces growth, S. arboricola is cryotolerant and thermosensitive [2,80,82]. Cryotolerance is a common attribute of yeast hybrids as seen in the lager yeast Saccharomyces pastorianus, which is a hybrid between S. cerevisiae $\times$ S. eubayanus [7,83-85]. This phenotype has proven beneficial for the cold fermentations typical of lagering beer or brewing sake. The ability to ferment at colder temperatures allows for more volatile compounds to be retained and a decrease in bitter or acidic taste [86]. The mechanism by which thermal phenotypes are determined has not been fully elucidated, but mitotype, ploidy, and lipid composition are factors [80,86-91]. Lipid profiles with a higher number of MCFA attributes to cryotolerance of S. cerevisiae x S. kudriavzevii hybrids [92]. At colder temperatures, increasing the MCFA composition and reducing saturated and unsaturated fatty acid composition allows increased fluidity of the membranes.

Previous reports show that wine yeast produce lower amino acidity and less succinic acid, but more malic acid than sake yeast [93]. Yeast strain has a major impact on metabolic profiles as seen in this study's two wine strains. During fermentation, organic acid production is attributed to the metabolism of pyruvate in the mitochondria and the reverse tricarboxylic acid cycle (TCA) cycle in the cytoplasm [94,95]. Most succinic acid and malic acid are produced through mitochondrial TCA cycle, however reductive TCA can supplement their production during sake fermentation [95]. These amino and organic acidity profiles are metabolically unique to individual strains and these may contribute a favorable fresh acidity such as malate while succinate contributes an unfavorable acidity to sake. During sake metabolic analysis, PC1 was inferred to represent the amino acid net uptake and mitochondrial transportation of pyruvate which contributes to the amino and organic acidity profiles (Figure 4 C). Of the sake metabolites detected, $75 \%$ of the compounds were produced in high abundance in the sake by S. arboricola as compared to S. cerevisiae which produced $44 \%$ of the compounds in high amounts. S. arboricola was considered to have a lower amino acid net uptake than S. cerevisiae strains in this study. The abundance of residual amino acids detected in the sake medium and the low abundance of endogenous metabolites were considered in these findings. Moreover, membrane fluidity and amino acid and organic acid transport of S. arboricola has not been investigated and merits further research.

The generated interspecific hybrids were considered to have vigorous glycolysis and fermentation of pyruvate to ethanol compared to parental strains. The reduced malic acid, succinic acid, and glucose (Figure 4A) compared to the increased ethanol yield (Figure 3A) supported these claims. The hybrid condition was distinctly exemplified in principal component 2 of the sake metabolite score plot. In this study, where parental metabolic profiles were similar, the hybrids revealed an inversion of these compounds in the heatmap as seen in DMTS, serine, urea, and succinic acid. DMTS is associated with the stale aroma of Japanese sake called hineka. Recycling of sulfur via the methionine salvage pathway produces DMTS-P1, a precursor of this aromatic compound [96]. Mercaptans (thiols) typically have a low sensory threshold and the hybrids were considered to have an active sulfur metabolism. Additionally, urea is a yeast waste product from arginase activity and can be catabolized to form succinate in the cell [97]. Mechanistic elucidation of these metabolic variances is beyond the scope of this initial report of sake fermentation by S. arboricola and the hybrids, further research is required. 
Research for S. arboricola yeast is very limited and one other report [80], to the author's knowledge, has explored their use and their interspecific hybrids' use in beverage fermentation. During their wort fermentation trials, S. arboricola produced high levels of ethyl hexanoate at $0.35 \mathrm{mg} \mathrm{mL}^{-1}$, while this study revealed low production at $0.207 \mathrm{mg} \mathrm{mL}^{-1}$ by substituting sake mash for wort. Yeast strain and raw ingredients certainly play a role in the final fermentation product qualities. The chemistry of sake and beer have some similarities, but there are also many differences including raw materials such as rice or barley and the presence of $A$. oryzae in the sake mash. These results indicate koji was an integral part of the sake mash converting rice carbohydrate into fermentable sugars. Aspergillus spp. produce mannitol at high levels $[46,47]$ and S. arboricola has great growth utilizing mannitol [14], but the bioavailability of this sugar for fermentation by $S$. arboricola remains unexplored. This metabolic capability likely facilitated the increase in fermentation performance seen in this study. S. arboricola and their hybrids may be uniquely fit for use in sake fermentations.

In two recent large phylogenetic analysis of 157 and 1011 Saccharomyces cerevisiae strains, an Asian cluster was found basal to the root of the trees [34,65] suggesting little divergence from their wild ancestors in comparison to the highly diverged beer1 clade. Although 1011 genome study was a great step in unmasking the lost ecology and domestication of natural Saccharomyces yeast, it had an overrepresentation of beer brewing strains. In order to dive deeper into the Out of Asia Origin Hypothesis, many more Asian and diverse strains will need to be sequenced and compared phylogenetically. The investigation into $S$. arboricola's biotechnological value yielded promising results, but the dynamics between A. oryzae's mannitol production and S. arboricola's mannitol utilization merits further research. Exploration of the biotechnical potential of the Saccharomyces clade is only now beginning and understanding the diversity of yeast facilitates humanity's exploitation of Saccharomyces.

\section{Conclusions}

This study explored the novel use of $S$. arboricola in Japanese rice wine known as sake, traditionally produced from polished rice with $A$. oryzae during winter months. The metabolites in the sake produced from S. arboricola, S. cerevisiae, and their interspecific hybrids were distinct by PCA analysis. S. arboricola had a lower amino acid net uptake than $S$. cerevisiae and the hybrids showed a mosaic profile of parental strains. Hybrid strains had a more vigorous ethanolic fermentation in the sake mash than S. cerevisiae but had a higher ethyl hexanoate yield than S. arboricola. In the ginjo style of Japanese sake, ethanol and ethyl hexanoate are important sensory metabolic compounds. S. arboricola differed from S. cerevisiae industrial strains because of lower levels of endogenous amino/organic acids, suggesting a lower amino acid net uptake. The endogenous metabolite study highlighted the impact of strain selection which industry niche has unwittingly had an influence in each strains metabolism. The diversity of the Saccharomyces clade of budding yeast is expansive and future studies focused metabolic phenotypes of new strains and novel applications will most likely surface in the following years to come.

Supplementary Materials: Supplementary materials can be found at http://www.mdpi.com/2311-5637/6/1/14/s1.

Author Contributions: Conceptualization, M.J.W., J.E.G.G., and H.K.; methodology, M.J.W.; validation, M.J.W., Y.Y., and Y.F.; formal analysis, M.J.W., Y.Y., and Y.F.; Investigation, M.J.W., Y.F., and Y.Y.; resources, H.K., Y.Y., Y.F., and Y.K.; data curation, Y.Y., Y.F., and Y.K.; writing — original draft preparation, M.J.W.; writing-review and editing, M.J.W., J.E.G.G., and H.K.; visualization, M.J.W., Y.F, and Y.Y.; supervision, H.K.; project administration, M.J.W. and H.K.; funding acquisition, M.J.W. and H.K. All authors have read and agreed to the published version of the manuscript.

Funding: This material is based upon work supported by the National Science Foundation's East Asia and Pacific Summer Institute Program [Grant No. 1713160], in conjunction with the Japanese Society for the Promotion of Science Summer Program ID: SP17053 to [MJW].

Acknowledgments: Thank you Jenny Bellon from the Austrian Wine Research Institute who aided with experimental design, Gianni Liti of Institute for Research on Cancer and Aging (IRCAN) who provided the Saccharomyces arboricola strains, Barbra Dunn of Stanford University who provided advice and materials, Angela $\mathrm{Chu} /$ Joe Horecka of Stanford University who shared their sporulation protocol, and Tetsuya Goshima/Takeshi Akao of the Japanese National Research Institute of Brewing (NRIB) who provided access to the micromanipulator and materials/provided the K7/868 haploid. 
Conflicts of Interest: Any opinions, findings, and conclusions or recommendations expressed in this material are those of the author(s) and do not necessarily reflect the views of the National Science Foundation.

\section{References}

1. Martini, A.V.; Martini, A. Three newly delimited species of Saccharomyces sensu stricto. Antonie Van Leeuwenhoek 1987, 53, 77-84. [CrossRef]

2. Wang, S.A.; Bai, F.Y. Saccharomyces arboricolus sp. nov., a yeast species from tree bark. Int. J. Syst. Evol. Microbiol. 2008, 58, 510-514. [CrossRef] [PubMed]

3. Naumova, E.S.; Roberts, I.N.; James, S.A.; Naumov, G.I.; Louis, E.J. Three new species in the Saccharomyces sensu stricto complex: Saccharomyces cariocanus, Saccharomyces kudriavzevii and Saccharomyces mikatae. Int. J. Syst. Evol. Microbiol. 2015, 50, 1931-1942. [CrossRef]

4. Naumov, G.I.; Naumova, E.S.; Hagler, A.N.; Mendonça-Hagler, L.C.; Louis, E.J. A new genetically isolated population of the Saccharomyces sensu stricto complex from Brazil. Antonie Van Leeuwenhoek 1995, 67, 351-355. [CrossRef]

5. Naumov, G.I.; Lee, C.-F.; Naumova, E.S. Molecular genetic diversity of the Saccharomyces yeasts in Taiwan: Saccharomyces arboricola, Saccharomyces cerevisiae and Saccharomyces kudriavzevii. Antonie Van Leeuwenhoek 2013, 103, 217-228. [CrossRef]

6. Naumov, G.I.; Naumova, E.S.; Louis, E.J. Two New Genetically Isolated Popoulations of the Saccharomyces Sensu Stricto Complex from Japan. J. Gen. Appl. Microbiol. 1995, 41, 499-505. [CrossRef]

7. Libkind, D.; Hittinger, C.T.; Valério, E.; Gonçalves, C.; Dover, J.; Johnston, M.; Gonçalves, P.; Sampaio, J.P. Microbe domestication and the identification of the wild genetic stock of lager-brewing yeast. Proc. Natl. Acad. Sci. USA 2011, 108, 14539-14544. [CrossRef] [PubMed]

8. Boynton, P.J.; Greig, D. The ecology and evolution of non-domesticated Saccharomyces species Primrose. Yeast 2014, 31, 449-462. [PubMed]

9. Sipiczki, M. Interspecies hybridisation and genome chimerisation in Saccharomyces: Combining of gene pools of species and its biotechnological perspectives. Front. Microbiol. 2018, 9, 3071. [CrossRef] [PubMed]

10. Masneuf, I.; Hansen, J.; Groth, C.; Piskur, J.; Dubourdieu, D. New hybrids between Saccharomyces sensu stricto yeast species found among wine and cider production strains. Appl. Environ. Microbiol. 1998, 64, 3887-3892. [CrossRef]

11. Querol, A.; Bond, U. The complex and dynamic genomes of industrial yeasts: Minireview. FEMS Microbiol. Lett. 2009, 293, 1-10. [CrossRef]

12. Nguyen, H.V.; Legras, J.L.; Neuvéglise, C.; Gaillardin, C. Deciphering the hybridisation history leading to the lager lineage based on the mosaic genomes of Saccharomyces bayanus strains NBRC1948 and CBS380 T. PLOS ONE 2011, 6, e25821. [CrossRef] [PubMed]

13. Gayevskiy, V.; Goddard, M.R. Saccharomyces eubayanus and Saccharomyces arboricola reside in North Island native New Zealand forests. Environ. Microbiol. 2016, 18, 1137-1147. [CrossRef] [PubMed]

14. Liti, G.; Nguyen Ba, A.N.; Blythe, M.; Müller, C.A.; Bergström, A.; Cubillos, F.A.; Dafhnis-Calas, F.; Khoshraftar, S.; Malla, S.; Mehta, N.; et al. High quality de novo sequencing and assembly of the Saccharomyces arboricolus genome. Bmc Genom. 2013, 14, 69. [CrossRef] [PubMed]

15. Cliften, P.; Sudarsanam, P.; Desikan, A.; Fulton, L.; Fulton, B.; Majors, J.; Waterston, R.; Cohen, B.A.; Johnston, M. Finding functional features in Saccharomyces genomes by phylogenetic footprinting. Science 2003, 301, 71-76. [CrossRef] [PubMed]

16. Birren, B.; Lander, E.S.; Kellis, M.; Endrizzi, M.; Patterson, N. Sequencing and comparison of yeast species to identify genes and regulatory elements. Nature 2003, 423, 241-254.

17. Liti, G.; Carter, D.M.; Moses, A.M.; Warringer, J.; Parts, L.; James, S.A.; Davey, R.P.; Roberts, I.N.; Burt, A.; Koufopanou, V.; et al. Population genomics of domestic and wild yeasts. Nature 2009, 458, 337-341. [CrossRef]

18. Dujon, B. Yeasts illustrate the molecular mechanisms of eukaryotic genome evolution. Trends Genet. 2006, 22, 375-387. [CrossRef]

19. Postma, E.; Verduyn, C.; Scheffers, A.; Van Dijken, J.P. Enzymic analysis of the Crabtree Effect in glucose-limited chemostat cultures of Saccharomyces cerevisiae. Appl. Environ. Microbiol. 1989, 55, 468-477. [CrossRef] 
20. Galdieri, L.; Mehrotra, S.; Yu, S.; Vancura, A. Transcriptional regulation in yeast during diauxic shift and stationary phase. OMI. J. Integr. Biol. 2010, 14, 629-638. [CrossRef]

21. McGovern, P.E.; Zhang, J.; Tang, J.; Zhang, Z.; Hall, G.R.; Moreau, R.A.; Nuñez, A.; Butrym, E.D.; Richards, M.P.; Wang, C.-S.; et al. Fermented beverages of pre- and proto-historic China. Proc. Natl. Acad. Sci. USA 2004, 101, 17593-17598. [CrossRef]

22. McGovern, P.E. Ancient Wine: The Search for the Origins of Viniculture; Princeton Publishing: Princeton, NJ, USA, 2003; pp. 1-15, ISBN 0691070806.

23. Kitagaki, H.; Kitamoto, K. Breeding Researches of Sake Yeasts in Japan: History, Recent Technological Advances, and Future Perspectives. Food Sci. Technol. 2012, 4, 215-235.

24. Charles, M.; Tang, H.; Belcram, H.; Paterson, A.; Gornicki, P.; Chalhoub, B. Sixty million years in evolution of soft grain trait in grasses: Emergence of the softness locus in the common ancestor of pooideae and ehrhartoideae, after their divergence from panicoideae. Mol. Biol. Evol. 2009, 26, 1651-1661. [CrossRef]

25. Arendt, E.; Zannini, E. Rice. In Cereal Grains for the Food and Beverage Industries; Woodhead Publishing: Cambridge, UK, 2013; pp. 114-154. ISBN 9780857098924.

26. Corran, H.S. A History of Brewing; David \& Charles: London, UK, 1975.

27. Sampaio, J.P. Microbe profile: Saccharomyces eubayanus, the missing link to lager beer yeasts. Microbiolog 2018, 164, 1069-1071. [CrossRef] [PubMed]

28. Peris, D.; Langdon, Q.K.; Moriarty, R.V.; Sylvester, K.; Bontrager, M.; Charron, G.; Leducq, J.B.; Landry, C.R.; Libkind, D.; Hittinger, C.T. Complex Ancestries of Lager-Brewing Hybrids Were Shaped by Standing Variation in the Wild Yeast Saccharomyces eubayanus. PLoS Genet. 2016, 12, e1006155. [CrossRef] [PubMed]

29. Nespolo, R.F.; Villarroel, C.A.; Oporto, C.I.; Tapia, S.M.; Vega, F.; Urbina, K.; De Chiara, M.; Mozzachiodi, S.; Mikhalev, E.; Thompson, D.; et al. An Out-of-Patagonia dispersal explains most of the worldwide genetic distribution in Saccharomyces eubayanus. bioRxiv 2019, 709253. [CrossRef]

30. Langdon, Q.K.; Peris, D.; Eizaguirre, J.I.; Opulente, D.A.; Buh, K.V.; Sylvester, K.; Jarzyna, M.; Rodríguez, M.E.; Lopes, C.A.; Libkind, D.; et al. Genomic diversity and global distribution of Saccharomyces eubayanus, the wild ancestor of hybrid lager-brewing yeasts. bioRxiv 2019, 709535.

31. Eizaguirre, J.I.; Peris, D.; Rodríguez, M.E.; Lopes, C.A.; De Los Ríos, P.; Hittinger, C.T.; Libkind, D. Phylogeography of the wild Lager-brewing ancestor (Saccharomyces eubayanus) in Patagonia. Environ. Microbiol. 2018, 20, 3732-3743. [CrossRef]

32. Nagy, L.G.; Ohm, R.A.; Kovács, G.M.; Floudas, D.; Riley, R.; Gácser, A.; Sipiczki, M.; Davis, J.M.; Doty, S.L.; De Hoog, G.S.; et al. Latent homology and convergent regulatory evolution underlies the repeated emergence of yeasts. Nat. Commun. 2014, 5, 4471. [CrossRef]

33. Bing, J.; Han, P.J.; Liu, W.Q.; Wang, Q.M.; Bai, F.Y. Evidence for a far east asian origin of lager beer yeast. Curr. Biol. 2014, 24, R380-R381. [CrossRef]

34. Peter, J.; De Chiara, M.; Friedrich, A.; Yue, J.X.; Pflieger, D.; Bergström, A.; Sigwalt, A.; Barre, B.; Freel, K.; Llored, A.; et al. Genome evolution across 1,011 Saccharomyces cerevisiae isolates. Nature 2018, 556, 339-344. [CrossRef]

35. Duan, S.F.; Han, P.J.; Wang, Q.M.; Liu, W.Q.; Shi, J.Y.; Li, K.; Zhang, X.L.; Bai, F.Y. The origin and adaptive evolution of domesticated populations of yeast from Far East Asia. Nat. Commun. 2018, 9, 2690. [CrossRef] [PubMed]

36. He, Y.; Dong, J.; Yin, H.; Zhao, Y.; Chen, R.; Wan, X.; Chen, P.; Hou, X.; Liu, J.; Chen, L. Wort composition and its impact on the flavour-active higher alcohol and ester formation of beer-A review. J. Inst. Brew. 2014, 120, 157-163. [CrossRef]

37. Engan, S. Wort Composition and Beer Flavour. II. The Influence of Different Carbohydrates on the Formation of Some Flavour Components During Fermentation. J. Inst. Brew. 1971, 78, 169-173. [CrossRef]

38. Younis, O.S.; Stewart, G.G. Sugar uptake and subsequent ester and higher alcohol production by Saccharomyces cerevisiae. J. Inst. Brew. 1998, 104, 255-264. [CrossRef]

39. Mortimer, R.; Polsinelli, M. On the origins of wine yeast. Res. Microbiol. 1999, 150, 199-204. [CrossRef]

40. Bisson, L.F. Gene Expression in Yeasts During Wine Fermentation. In Yeasts in The Production of Wine; Romano, P., Ciani, M., Fleet, G., Eds.; Springer: New York, NY, USA, 2019; pp. 165-209.

41. Kühbeck, F.; Back, W.; Krottenthaler, M. Influence of lauter turbidity on wort composition, fermentation performance and beer quality-A review. J. Inst. Brew. 2006, 112, 215-221. [CrossRef] 
42. White, C.; Zainasheff, J. Yeast: The Practical Guide to Beer Fermentation (Brewing Elements); Brewers Publications: Boulder, CO, USA, 2010.

43. Kodama, K. Sake Yeast. In The Yeasts; Rose, H., Harrison, J.S., Eds.; Academic Press: London, UK, 1993; pp. 129-168.

44. Ferdouse, J.; Yamamoto, Y.; Taguchi, S.; Yoshizaki, Y.; Takamine, K.; Kitagaki, H. Glycosylceramide modifies the flavor and metabolic characteristics of sake yeast. PeerJ 2018, 10, e4768. [CrossRef]

45. Zhang, B.; Guan, Z.B.; Cao, Y.; Xie, G.F.; Lu, J. Secretome of Aspergillus oryzae in Shaoxing rice wine koji. Int. J. Food Microbiol. 2012, 155, 113-119. [CrossRef]

46. Song, S.H.; Vieille, C. Recent advances in the biological production of mannitol. Appl. Microbiol. Biotechnol. 2009, 84, 55-62. [CrossRef]

47. Smiley, K.L.; Cadmus, M.C.; Liepins, P. Biosynthesis of D-mannitol from D-glucose by Aspergillus candidus. Biotechnol. Bioeng. 1967, 9, 365-374. [CrossRef]

48. Bellon, J.R.; Schmid, F.; Capone, D.L.; Dunn, B.L.; Chambers, P.J. Introducing a New Breed of Wine Yeast: Interspecific Hybridisation between a Commercial Saccharomyces cerevisiae Wine Yeast and Saccharomyces mikatae. PLoS ONE 2013, 8, e62053. [CrossRef] [PubMed]

49. González, S.S.; Barrio, E.; Gafner, J.; Querol, A. Natural hybrids from Saccharomyces cerevisiae, Saccharomyces bayanus and Saccharomyces kudriavzevii in wine fermentations. FEMS Yeast Res. 2006, 6, 1221-1234. [CrossRef] [PubMed]

50. Capece, A.; Romaniello, R.; Siesto, G.; Romano, P. Diversity of Saccharomyces cerevisiae yeasts associated to spontaneously fermenting grapes from an Italian "heroic vine-growing area". Food Microbiol. 2012, 31, 159-166. [CrossRef] [PubMed]

51. Song, G.; Dickins, B.J.A.; Demeter, J.; Engel, S.; Dunn, B.; Cherry, J.M. AGAPE (Automated Genome Analysis PipelinE) for pan-genome analysis of Saccharomyces cerevisiae. PLoS ONE 2015, 10, e0120671. [CrossRef]

52. Katou, T.; Kitagaki, H.; Akao, T.; Shimoi, H. Brewing characteristics of haploid strains isolated from sake yeast Kyokai No. Yeast 2008, 25, 799-807. [CrossRef]

53. Horie, K.; Oba, T.; Motomura, S.; Isogai, A.; Yoshimura, T.; Tsuge, K.; Koganemaru, K.; Kobayashi, G.; Kitagaki, H. Breeding of a Low Pyruvate-Producing Sake Yeast by Isolation of a Mutant Resistant to Ethyl $\alpha$-Transcyanocinnamate, an Inhibitor of Mitochondrial Pyruvate Transport. Biosci. Biotechnol. Biochem. 2010, 74, 843-847. [CrossRef]

54. Sniegowski, P.D.; Dombrowski, P.G.; Fingerman, E. Saccharomyces cerevisiae and Saccharomyces paradoxus coexist in a natural woodland site in North America and display different levels of reproductive isolation from European conspecifics. FEMS Yeast Res. 2002, 1, 299-306.

55. Schoch, C.L.; Seifert, K.A.; Huhndorf, S.; Robert, V.; Spouge, J.L.; Levesque, C.A.; Chen, W.; Consortium, F.B.; Bolchacova, E.; Voigt, K.; et al. Nuclear ribosomal internal transcribed spacer (ITS) region as a universal DNA barcode marker for Fungi. Proc. Natl. Acad. Sci. USA 2012, 109, 1-6. [CrossRef]

56. Rong-Mullins, X.; Winans, M.J.; Lee, J.B.; Lonergan, Z.R.; Pilolli, V.A.; Weatherly, L.M.; Carmenzind, T.W.; Jiang, L.; Cumming, J.R.; Oporto, G.S.; et al. Proteomic and genetic analysis of the response of S. cerevisiae to soluble copper leads to improvement of the antimicrobial function of cellulosic copper nanoparticles. Metallomics 2017, 9, 1304-1315. [CrossRef]

57. Shimwell, J.L. A Simple Staining Method for the Detection of Ascospores in Yeasts. J. Inst. Brew. 1938, 44, 474. [CrossRef]

58. Muir, A.; Harrison, E.; Wheals, A. A multiplex set of species-specific primers for rapid identification of members of the genus Saccharomyces. FEMS Yeast Res. 2011, 11, 552-563. [CrossRef] [PubMed]

59. Korbie, D.J.; Mattick, J.S. Touchdown PCR for increased specificity and sensitivity in PCR amplification. Nat. Protoc. 2008, 3, 1452-1456. [CrossRef] [PubMed]

60. Lee, P.Y.; Costumbrado, J.; Hsu, C.-Y.; Kim, Y.H. Agarose Gel Electrophoresis for the Separation of DNA Fragments. J. Vis. Exp. 2012, 20, e3923. [CrossRef]

61. Xia, J.; Sinelnikov, I.V.; Han, B.; Wishart, D.S. MetaboAnalyst 3.0-making metabolomics more meaningful. Nucleic Acids Res. 2015, 43, W251-W257. [CrossRef]

62. Berthels, N.J.; Cordero Otero, R.R.; Bauer, F.F.; Thevelein, J.M.; Pretorius, I.S. Discrepancy in glucose and fructose utilisation during fermentation by Saccharomyces cerevisiae wine yeast strains. FEMS Yeast Res. 2004, 4, 683-689. [CrossRef] 
63. Berthels, N.J.; Cordero Otero, R.R.; Bauer, F.F.; Pretorius, I.S.; Thevelein, J.M. Correlation between glucose/fructose discrepancy and hexokinase kinetic properties in different Saccharomyces cerevisiae wine yeast strains. Appl. Microbiol. Biotechnol. 2008, 77, 1083-1091. [CrossRef]

64. Melcher, K.; Entian, K.-D. Genetic analysis of serine biosynthesis and glucose repression in yeast. Curr. Genet. 1992, 21, 295-300. [CrossRef]

65. Gallone, B.; Steensels, J.; Baele, G.; Maere, S.; Verstrepen, K.J.; Prahl, T.; Soriaga, L.; Saels, V.; Herrera-Malaver, B.; Merlevede, A.; et al. Domestication and Divergence of Saccharomyces cerevisiae Beer Yeasts. Cell 2016, 166, 1397-1410.e16. [CrossRef]

66. Dunn, B.; Richter, C.; Kvitek, D.J.; Pugh, T.; Sherlock, G. Analysis of the Saccharomyces cerevisiae pan-genome reveals a pool of copy number variants distributed in diverse yeast strains from differing industrial environments. Genome Res. 2012, 22, 908-924. [CrossRef]

67. Bergström, A.; Simpson, J.T.; Salinas, F.; Barré, B.; Parts, L.; Zia, A.; Nguyen Ba, A.N.; Moses, A.M.; Louis, E.J.; Mustonen, V.; et al. A high-definition view of functional genetic variation from natural yeast genomes. Mol. Biol. Evol. 2014, 31, 872-888. [CrossRef] [PubMed]

68. Verstrepen, K.J.; Derdelinckx, G.; Dufour, J.P.; Winderickx, J.; Thevelein, J.M.; Pretorius, I.S.; Delvaux, F.R. Flavor-active esters: Adding fruitiness to beer. J. Biosci. Bioeng. 2003, 96, 110-118. [CrossRef]

69. Pisarnitskii, A.F. Formation of wine aroma: Tones and imperfections caused by minor components (review). Appl. Biochem. Microbiol. 2001, 37, 552-560. [CrossRef]

70. Pretorius, I.S.; Lambrechts, M.G. Yeast and its importance to wine aroma: A review. S. Afr. J. Enol. Vitic. 2000, 21, 97-129.

71. Quilter, M.G.; Hurley, J.C.; Lynch, F.J.; Murphy, M.G. The Production of Isoamyl Acetate from Amyl Alcohol by Saccharomyces cerevisiae. J. Inst. Brew. 2003, 109, 34-40. [CrossRef]

72. Verstrepen, K.J.; Van Laere, S.D.M.; Vanderhaegen, B.M.P.; Derdelinckx, G.; Dufour, J.-P.; Pretorius, I.S.; Winderickx, J.; Thevelein, J.M.; Delvaux, F.R. Expression Levels of the Yeast Alcohol Acetyltransferase Genes ATF1, Lg-ATF1, and ATF2 Control the Formation of a Broad Range of Volatile Esters. Appl. Environ. Microbiol. 2003, 69, 5228-5237. [CrossRef]

73. Norstedt, C.; Bengtsson, A.; Bennet, P.; Lindström, I.; Äyräpää, T. Technical Measures to Control the Formation of Esters During Beer Fermentation. In Proceedings of the European Brewery Convention: Proceedings of the 15th Congress; Elsevier Scientific Publishing Company: Amsterdam, The Netherlands, 1975; pp. 581-600.

74. Hammond, J.R.M. Yeast Technology. In Brewer's Yeast; Rose, A.H., Harrison, J.S., Eds.; Academic Press: San Diego, CA, USA, 1993; Volumne 5, pp. 8-56.

75. Takahashi, T.; Ohra, Y.; Sueno, K. Breeding of a sake yeast mutant with enhanced ethyl caproate productivity in sake brewing using rice milled at a high polishing ratio. J. Biosci. Bioeng. 2017, 123, 707-713. [CrossRef]

76. Furukawa, K.; Yamada, T.; Mizoguchi, H.; Hara, S. Increased Ethyl Caproate Production by Inositol Limitation in Saccharomyces cerevisiae. J. Biosci. Bioeng. 2003, 95, 448-454. [CrossRef]

77. Dittrich-Reed, D.R.; Fitzpatrick, B.M. Transgressive Hybrids as Hopeful Monsters. Evol. Biol. 2013, 40, 310-315. [CrossRef]

78. Bisson, L.F. Yeast Hybrids in Winemaking. Catal. Discov. Pract. 2017, 1, 27-34. [CrossRef]

79. Morales, L.; Dujon, B. Evolutionary Role of Interspecies Hybridization and Genetic Exchanges in Yeasts. Microbiol. Mol. Biol. Rev. 2012, 76, 721-739. [CrossRef]

80. Nikulin, J.; Krogerus, K.; Gibson, B. Alternative Saccharomyces interspecies hybrid combinations and their potential for low-temperature wort fermentation. Yeast 2018, 35, 113-127. [CrossRef]

81. Peris, D.; Moriarty, R.V.; Alexander, W.G.; Baker, E.C.; Sylvester, K.; Sardi, M.; Langdon, Q.K.; Libkind, D.; Wang, Q.M.; Bai, F.Y.; et al. Hybridization and adaptive evolution of diverse Saccharomyces species for cellulosic biofuel production. Biotechnol. Biofuels 2017, 10, 1-19. [CrossRef] [PubMed]

82. Salvadó, Z.; Arroyo-López, F.N.; Guillamón, J.M.; Salazar, G.; Querol, A.; Barrio, E. Temperature adaptation Markedly Determines evolution within the genus Saccharomyces. Appl. Environ. Microbiol. 2011, 77, 2292-2302. [CrossRef]

83. Krogerus, K.; Magalhes, F.; Vidgren, V.; Gibson, B. New lager yeast strains generated by interspecific hybridization. J. Ind. Microbiol. Biotechnol. 2015, 769-778. [CrossRef] [PubMed]

84. Magalhães, F.; Krogerus, K.; Vidgren, V.; Sandell, M.; Gibson, B. Improved cider fermentation performance and quality with newly generated Saccharomyces cerevisiae $\times$ Saccharomyces eubayanus hybrids. J. Ind. Microbiol. Biotechnol. 2017, 44, 1203-1213. [CrossRef] [PubMed] 
85. Magalhães, F.; Krogerus, K.; Castillo, S.; Ortiz-Julien, A.; Dequin, S.; Gibson, B. Exploring the potential of Saccharomyces eubayanus as a parent for new interspecies hybrid strains in winemaking. FEMS Yeast Res. 2017, 17, 1-10. [CrossRef]

86. Torija, M.J.; Beltran, G.; Novo, M.; Poblet, M.; Guillamón, J.M.; Mas, A.; Rozès, N. Effects of fermentation temperature and Saccharomyces species on the cell fatty acid composition and presence of volatile compounds in wine. Int. J. Food Microbiol. 2003, 85, 127-136. [CrossRef]

87. Krogerus, K.; Magalhães, F.; Vidgren, V.; Gibson, B. Novel brewing yeast hybrids: Creation and application. Appl. Microbiol. Biotechnol. 2017, 101, 65-78. [CrossRef]

88. Fay, J.C.; Hittinger, C.T.; Sia, E.A.; Peris, D.; Li, X.C. Mitochondria-encoded genes contribute to evolution of heat and cold tolerance in yeast. Sci. Adv. 2019, 5, eaav1848.

89. Beltran, G.; Novo, M.; Guillamón, J.M.; Mas, A.; Rozès, N. Effect of fermentation temperature and culture media on the yeast lipid composition and wine volatile compounds. Int. J. Food Microbiol. 2008, 121, 169-177. [CrossRef] [PubMed]

90. Redón, M.; Guillamón, J.M.; Mas, A.; Rozès, N. Effect of lipid supplementation upon Saccharomyces cerevisiae lipid composition and fermentation performance at low temperature. Eur. Food Res. Technol. 2009, 228, 833-840. [CrossRef]

91. Baker, E.P.; Peris, D.; Moriarty, R.V.; Li, X.C.; Fay, J.C.; Hittinger, C.T. Mitochondrial DNA and temperature tolerance in lager yeasts. Sci. Adv. 2019, 5, eaav1869. [CrossRef] [PubMed]

92. Tronchoni, J.; Rozès, N.; Querol, A.; Guillamón, J.M. Lipid composition of wine strains of Saccharomyces kudriavzevii and Saccharomyces cerevisiae grown at low temperature. Int. J. Food Microbiol. 2012, 155, 191-198. [CrossRef] [PubMed]

93. Iwase, T.; Takada, A.; Watanade, T.; Fukuda, H.; Sasaki, K.; Yoshitake, M. Breeding of Sake Yeast by Protoplast Fusion of Sake Yeast and Wine Yeast. J. Brew. Soc. Jpn. 1995, 90, 137-142. [CrossRef]

94. Motomura, S.; Horie, K.; Kitagaki, H. Mitochondrial activity of sake brewery yeast affects malic and succinic acid production during alcoholic fermentation. J. Inst. Brew. 2012, 118, 22-26. [CrossRef]

95. Asano, T.; Kurose, N.; Hiraoka, N.; Kawakita, S. Effect of NAD+-dependent isocitrate dehydrogenase gene (IDH1, IDH2) disruption of sake yeast on organic acid composition in sake mash. J. Biosci. Bioeng. 1999, 88, 258-263. [CrossRef]

96. Wakabayashi, K.; Isogai, A.; Watanabe, D.; Fujita, A.; Sudo, S. Involvemwnt of methionine salvage pathway genes of Saccharomyces cerevisiae in the production of precursor compounds of dimethyl trisulfide (DMTS). J. Biosci. Bioeng. 2013, 116, 475-479. [CrossRef]

97. Schneider, B.L.; Kiupakis, A.K.; Reitzer, L.J. Arginine catabolism and the arginine succinyltransferase pathway in Escherichia coli. J. Bacteriol. 1998, 180, 4278-4286. [CrossRef] 